2 Chemolithoautotropic diazotrophy dominates the nitrogen

4 Xiaoxu Sun ${ }^{1,2,3}$, Tianle Kong ${ }^{1,4}$, Max M. Häggblom ${ }^{5}$, Max Kolton ${ }^{1}$, Fangbai Li ${ }^{1,2,3}$, Yiran

5 Dong ${ }^{6}$, Yuqing Huang ${ }^{1}$, Baoqin $\mathrm{Li}^{1}$, Weimin Sun ${ }^{1,2,3 *}$

6 1. Guangdong Key Laboratory of Integrated Agro-environmental Pollution Control and

7 Management, Guangdong Institute of Eco-environmental Science \& Technology,

8 Guangzhou 510650, China

9 2. National-Regional Joint Engineering Research Center for Soil Pollution Control and

10 Remediation in South China, Guangzhou 510650, China

11 3. Guangdong-Hong Kong-Macao Joint Laboratory for Environmental Pollution and 12 Control, Guangzhou 510650, China

13 4. School of Environmental Science and Engineering, Guangzhou University, 14 Guangzhou 510006, China

15 5. Department of Biochemistry and Microbiology, Rutgers University, New Brunswick NJ $16 \quad 08901$, USA

17 6. School of Environmental Studies, China University of Geosciences (Wuhan), Wuhan $18 \quad 430074$, China

$20{ }^{*}$ Correspondence to:

21 Dr. Weimin Sun

22808 Tianyuan Road, Guangzhou, Guangdong, China

23 Phone: 86-020-87024633 
24 Fax: 86-020-87024123

25 Email:wmsun@soil.gd.cn

26

27 Keywords: Tailing, nitrogen fixation, sulfur oxidation, carbon fixation, remediation.

28

29 The Supporting Information contains 14 figures and 4 tables. The Supplementary Figures

30 have a total of 22 pages.

31 


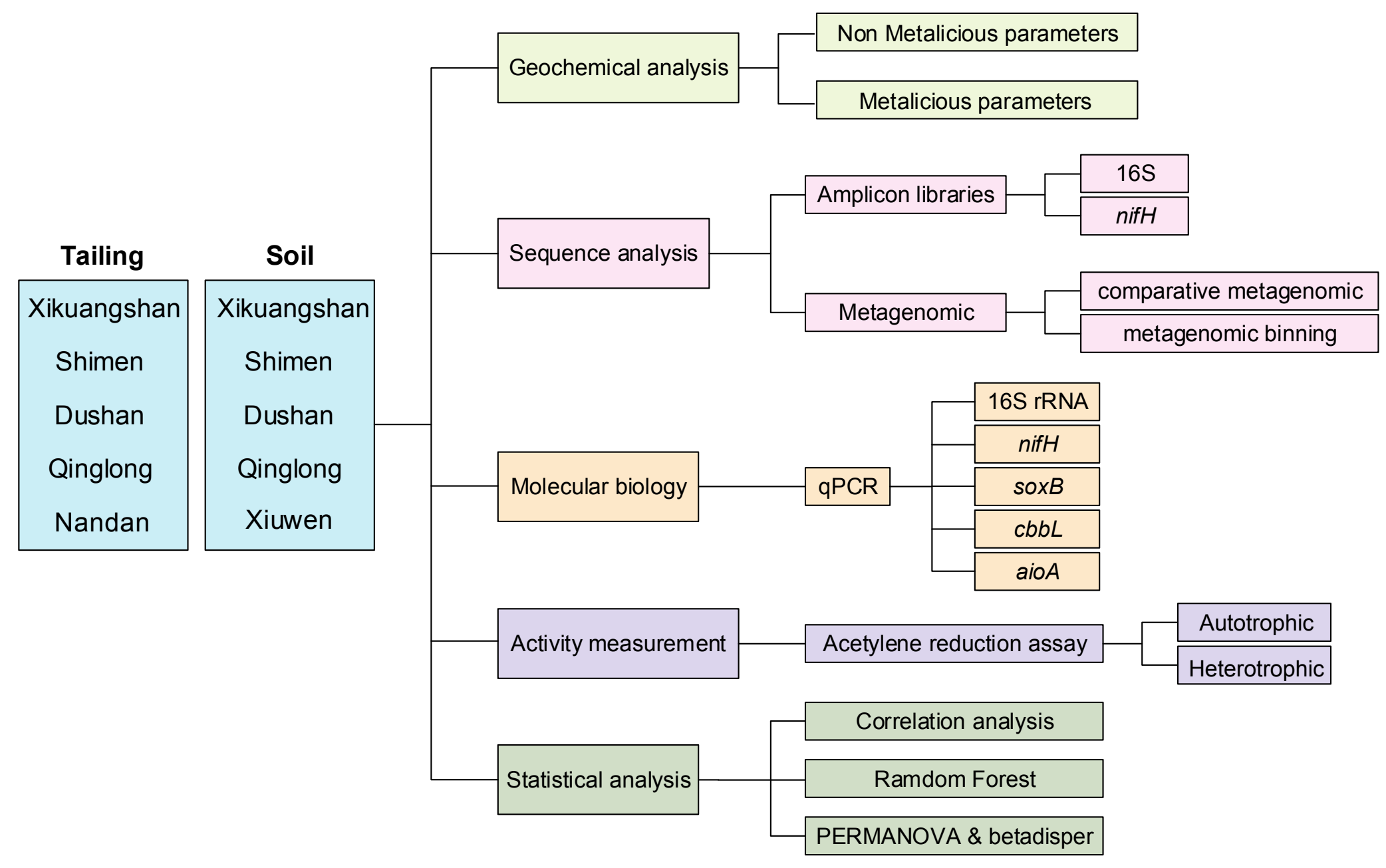

33 Fig. S1. Overview of the experimental design employing a combination of geochemical analysis, bioinformatics, molecular 34 biology, activity measurements, and statistical analysis to elucidate the energy production and carbon utilization pathways 35 of the nitrogen-fixing microbial community in tailings. 


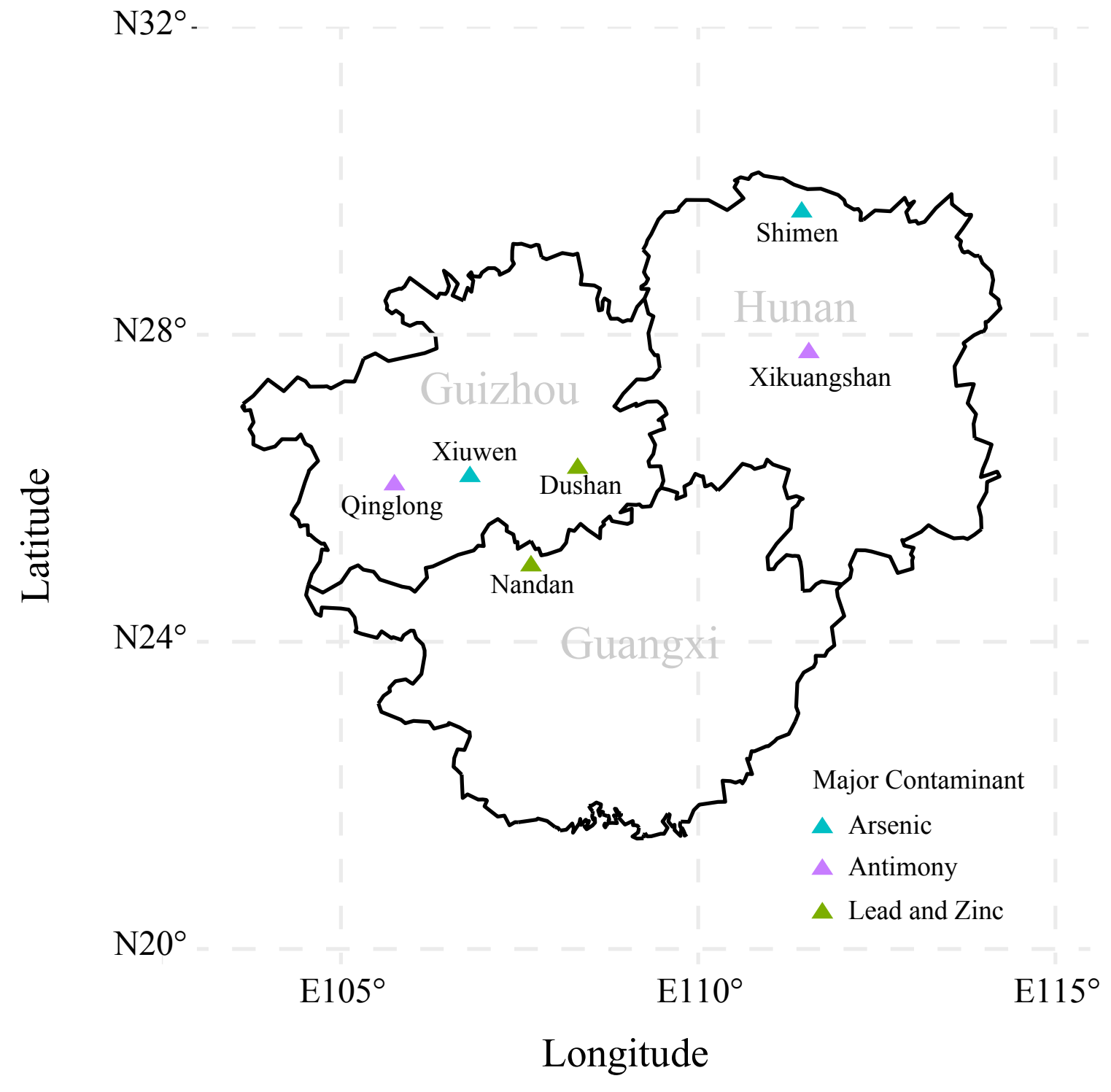

37 Fig. S2. Sampling locations for tailings and adjacent soils in southern China. The legend 38 shows the major contaminant of the site.

39

40 

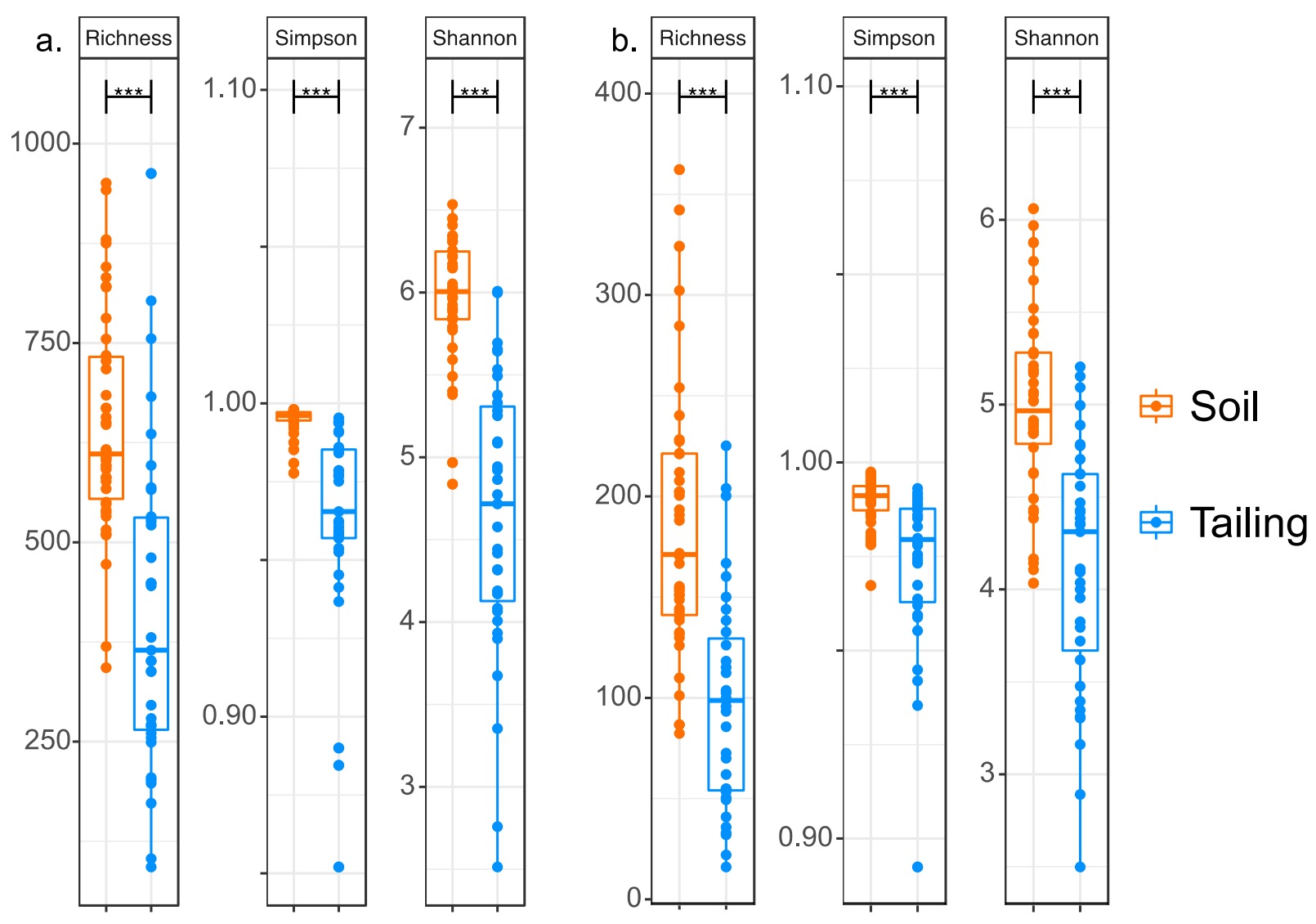

42 Fig. S3. The alpha diversity measured in three indices of the prokaryotic (a) and 43 diazotrophic (b) microbial communities. Samples were rarefied to the number of counts 44 in the lowest libraries. The ${ }^{*}$ sign represents the statistical significance between the 45 sample types $\left(^{* * *}\right.$ indicates $\left.p<0.001\right)$.

46 
a. (a) and diazotrophic (b) microbial communities.

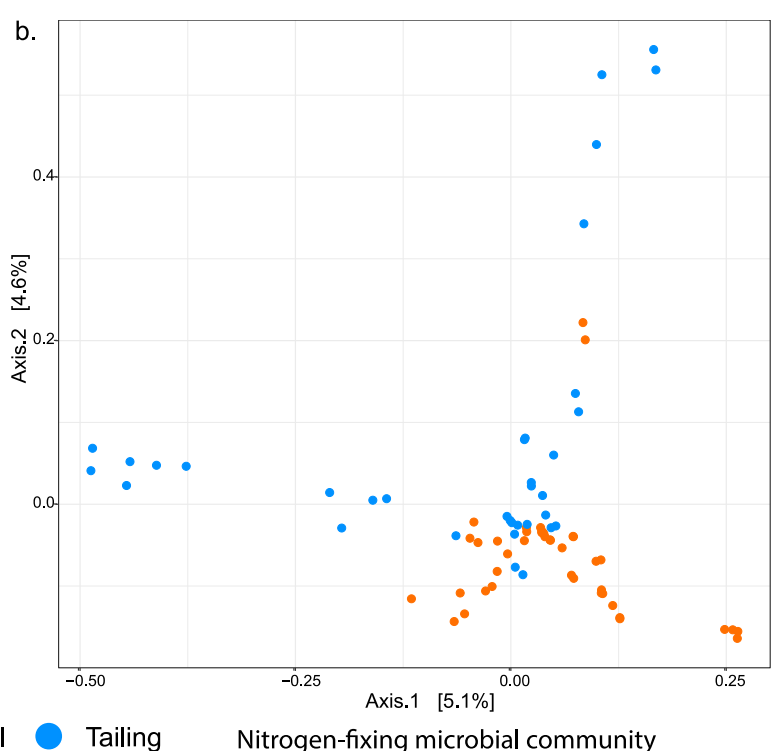

Soil

Tailing

Nitrogen-fixing microbial community

48 Fig. S4. PCoA plots of beta similarities measured as Bray-Curtis distances for prokaryotic

50 


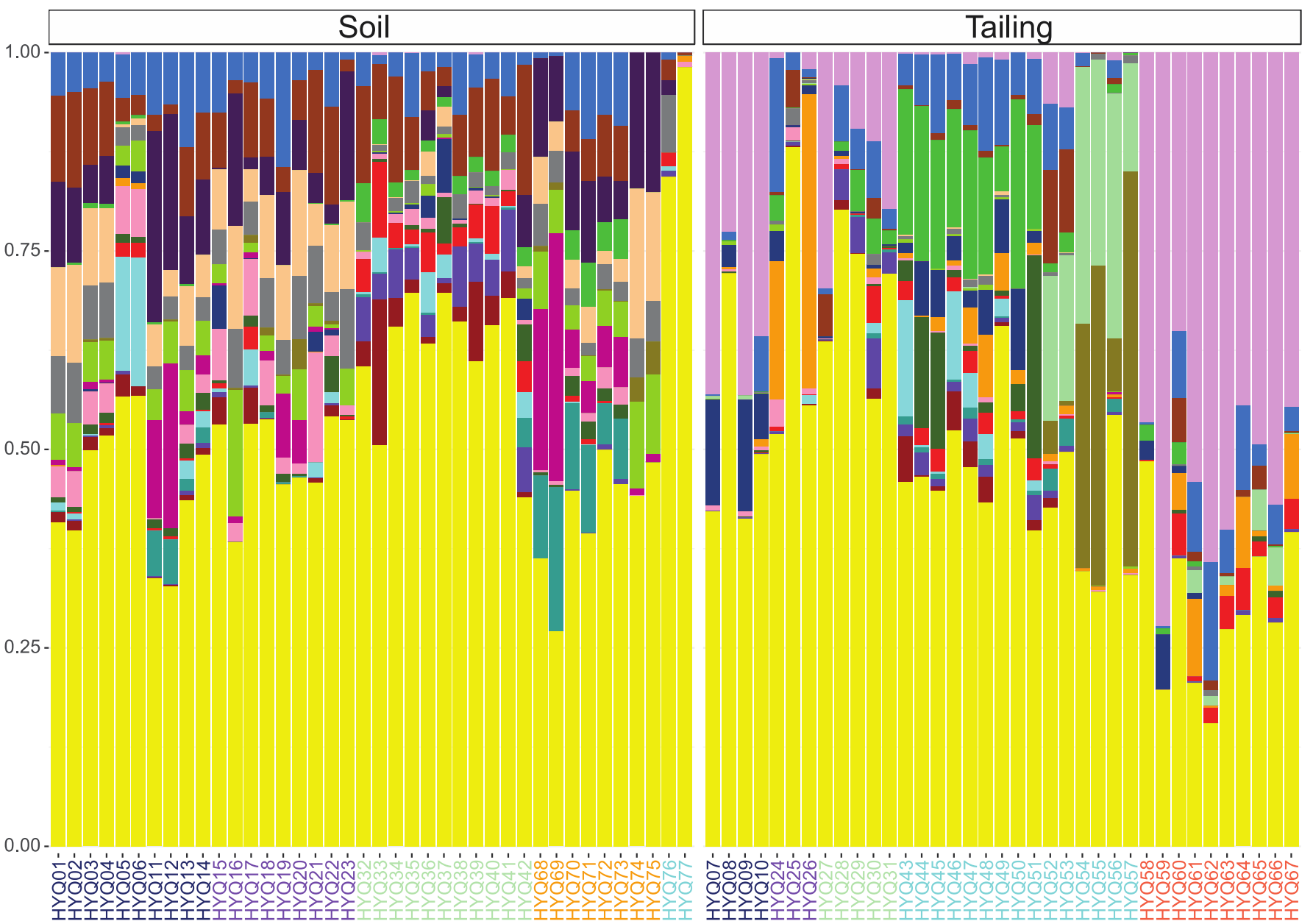

Taxa

- Thiobacillus

- Sphingomonas

Gemmatimonas

Acidothermus

- Pseudarthrobacter

- Candidatus Solibacter

- Bryobacter

- Sulfuriferula

- Rhodanobacter

- Acidibacter

- Burkholderia.Paraburkholderia

- Arenimonas

- Sulfurifustis

- Haliangium

- Massilia

- Gaiella

- RB41

- Arthrobacter

- Nocardioides

- Roseiflexus

- Others

\section{Sample site}

Xikuangshan

Shimen

Dushan

Qinglong

Nandan

Lanmuchang

Fig. S5. Prokaryotic microbial community composition based on the $16 \mathrm{~S}$ rRNA gene. The barplot shows the relative abundance of each genus in each individual sample. 


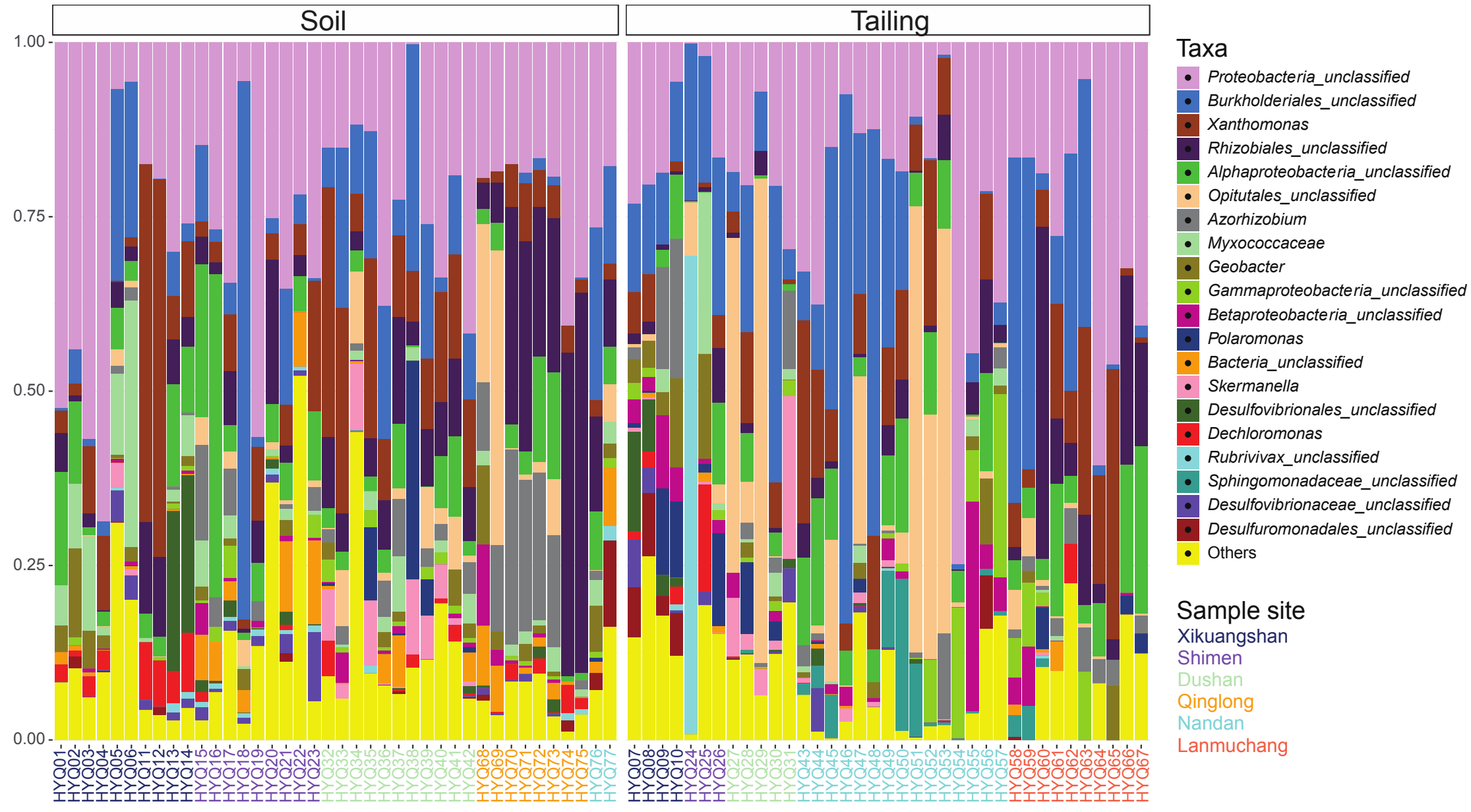

Fig. S6. Diazotrophic microbial community composition based on the nifH gene. The barplot shows the relative 57 abundance of each genus in each individual sample. 


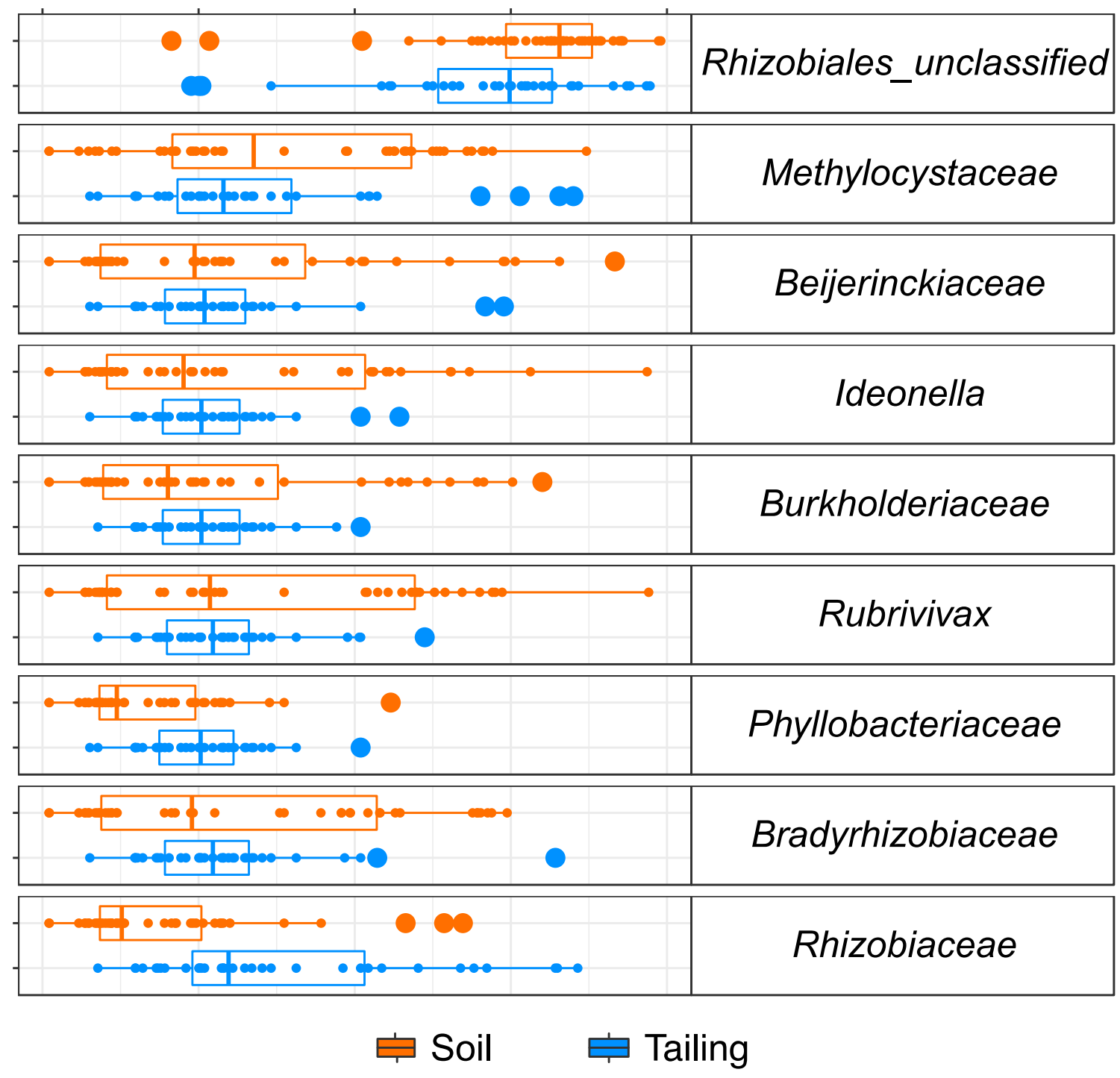

Fig. S7. Boxplot showing the differential distribution of the major diazotrophic groups

60 between the soils and the tailings calculated by Kruskal-Wallis test. Taxa are clustered 61 at the family level. 

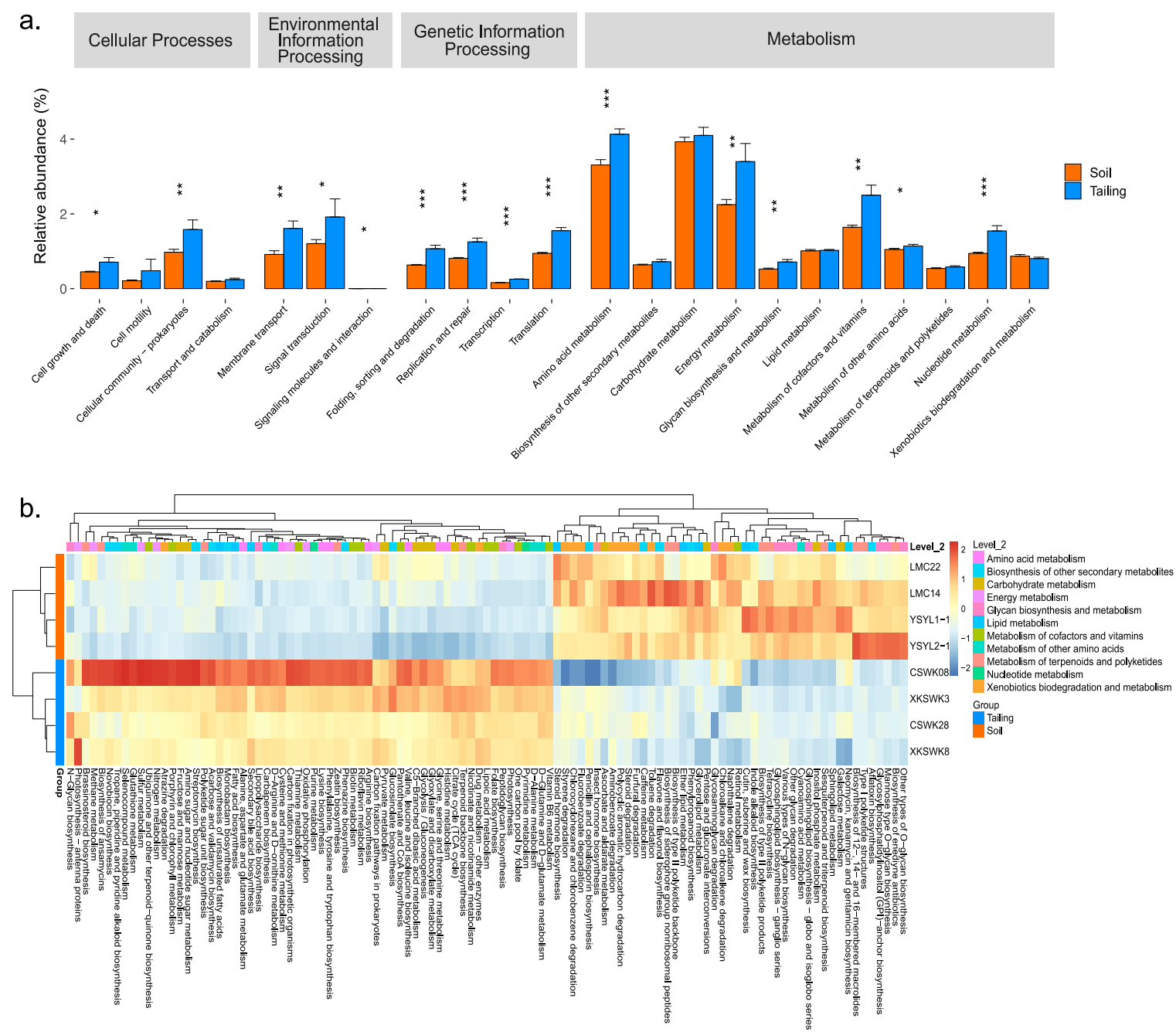

63 Fig. S8. Relative abundance (a) of the community functional compositions of the Level 2

64 KEGG pathways. The assigned reads are normalized to the number of the total 65 sequences. The * sign represents the statistical significance between the sample types 66 ( ${ }^{*}$ indicates $p<0.05,{ }^{* *}$ indicates $p<0.01,{ }^{* * *}$ indicates $\left.p<0.001\right)$. The heatmap (b)

67 shows the relative distribution of the individual level 3 KEGG functional pathways. The 68 reads are normalized to the total number of sequences in each sample. The pathways 69 enriched in the samples are shown in red color, the pathways depleted in the samples

70 are shown in blue color. The colors on top of the graph shows the affiliation of the 71 pathways to the level 2 KEGG pathways. 


\section{2}

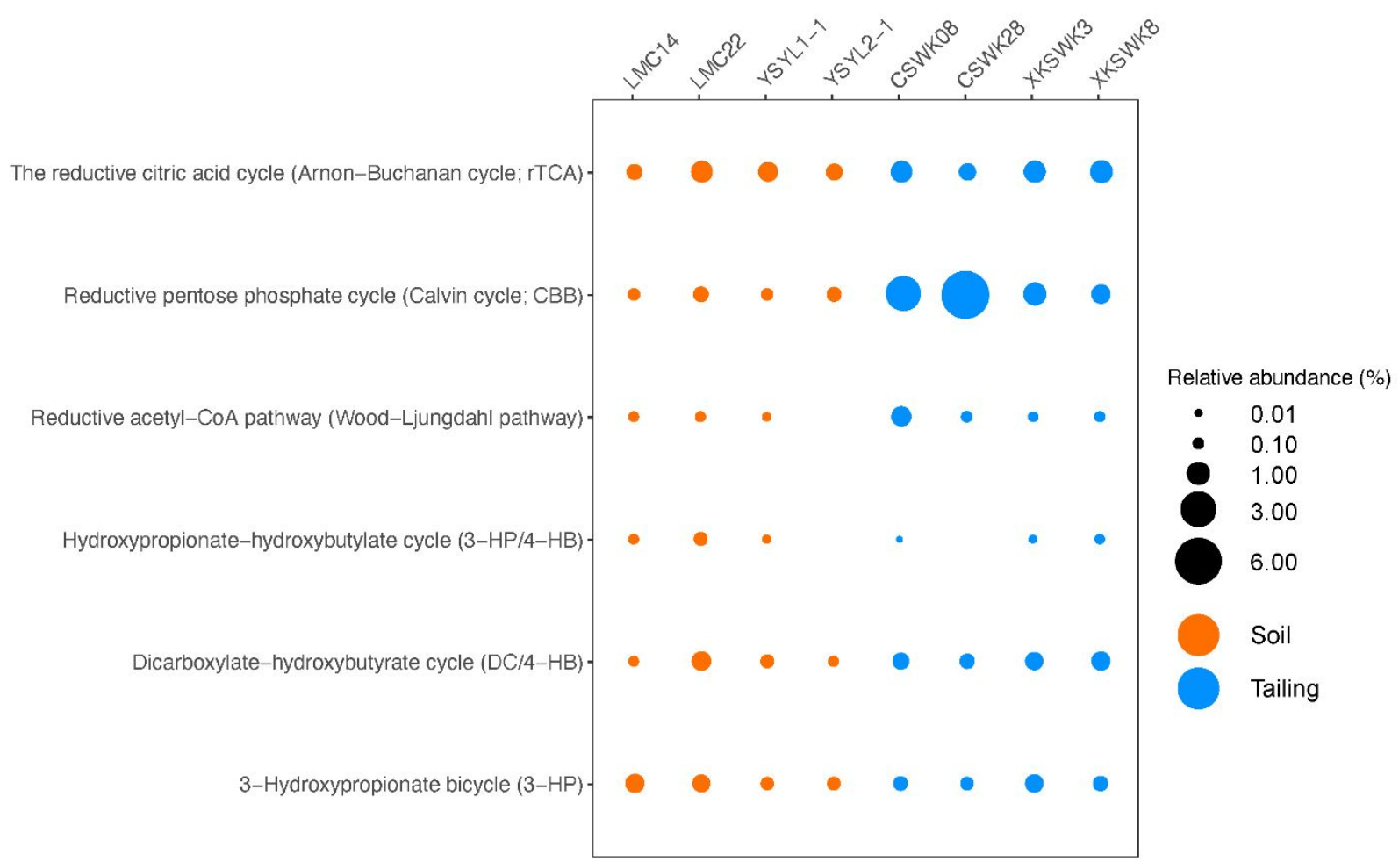

73

74 Fig. S9. Percentage of reads assigned to pathways related to carbon fixation in

75 prokaryotes in each sample. The relative abundance was calculated by normalizing

76 assigned reads to the total number of sequences. The size of the dot is proportion to the

77 relative abundance. 


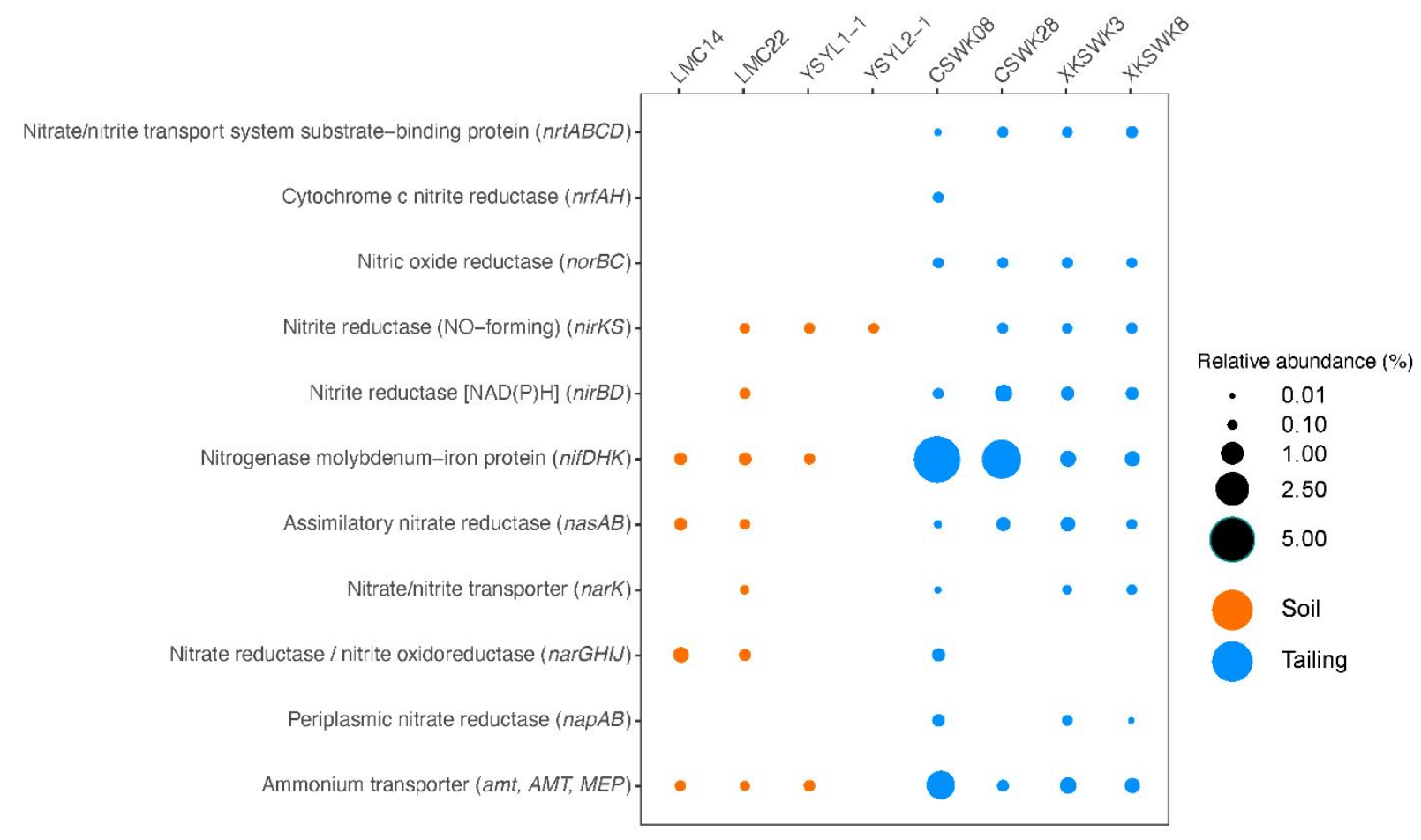

79 Fig. S10. Percentage of reads assigned to pathways related to nitrogen metabolism in 80 each sample. The relative abundance was calculated by normalizing assigned reads to 81 the total number of sequences. The size of the dot is proportion to the relative abundance. 82 


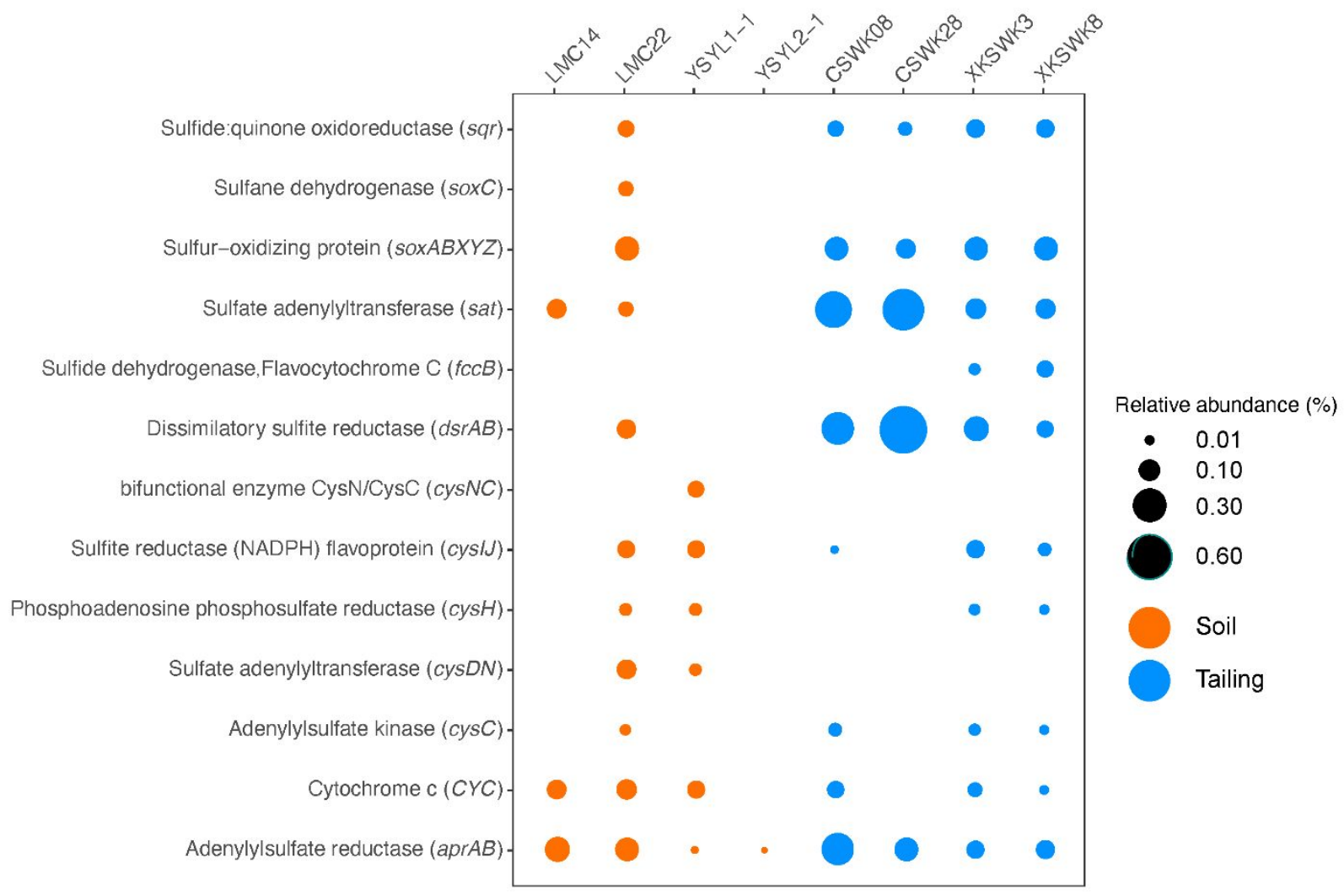

84 Fig. S11. Percentage of reads assigned to pathways related to sulfur cycling in each

85 sample. The relative abundance was calculated by normalizing assigned reads to the 86 total number of sequences. The size of the dot is proportion to the relative abundance.

87

88 
Tree scale: 1

\section{Classification}

Droteobacteria

- Actinobacteria

$\square$ Archaea

- Bacteroidetes

$\square$ Chlorobi

$\square$ Chloroflexi

$\square$ Firmicutes

$\square$ Gemmatimonadetes

$\square$ Nitrospirae

$\square$ Planctomycetes

$\square$ Thermotogae

$\square$ Undefined Bacteria

$\square$ Verrucomicrobia

\section{Bins' position}

$\star$ Bin

Sequencing depth

$\square$ Tailing

$\square$ Soil

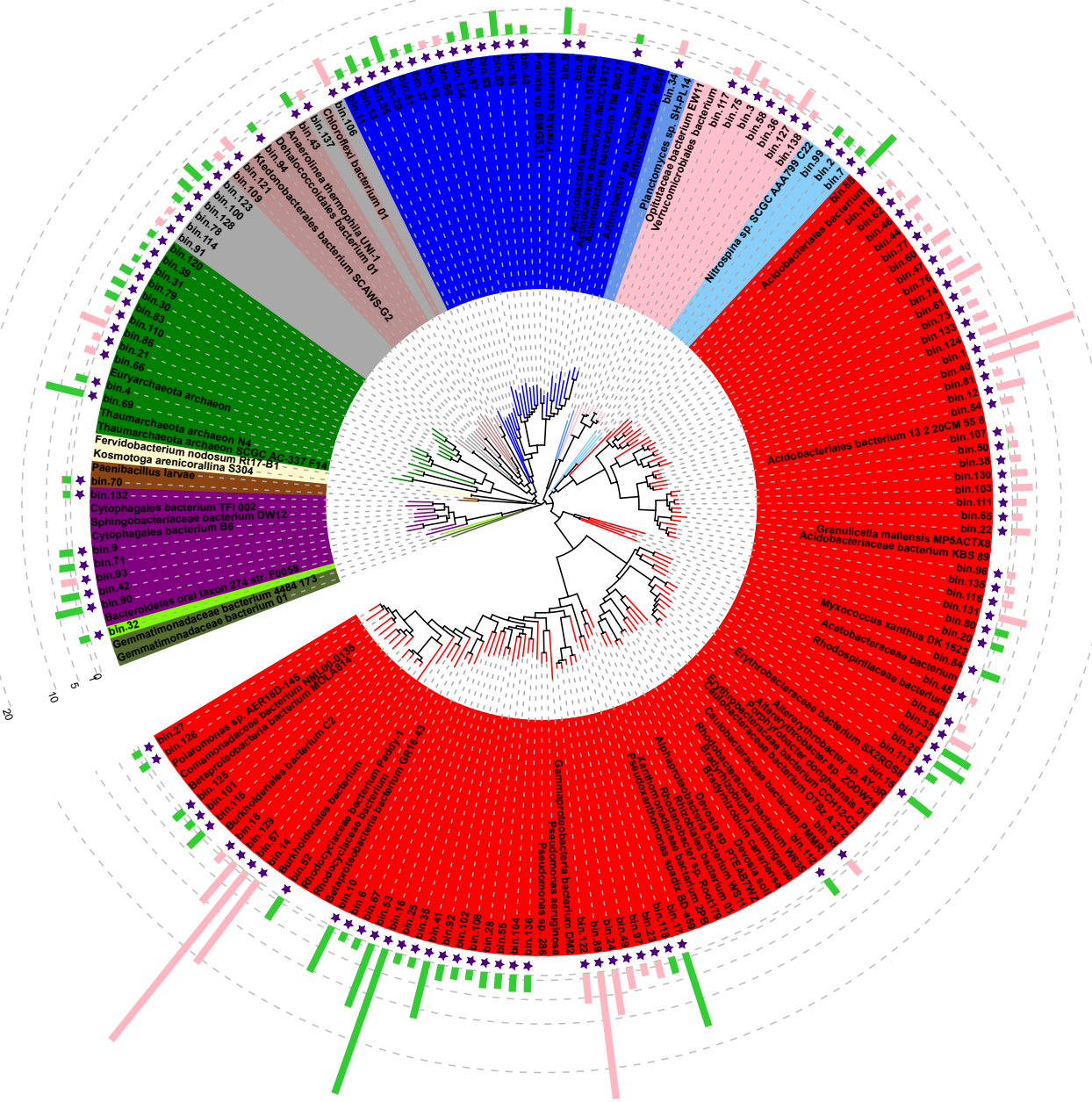

90 Fig. S12. Phylogenetic tree with reference genomes with the bars indicating the

91 distribution of the MAGs between the soils and the tailings. 
CARBON FIXATION PATHWAYS IN PROKARYOTES

bin28 bin41 bin57 bin99 bin102 bin117

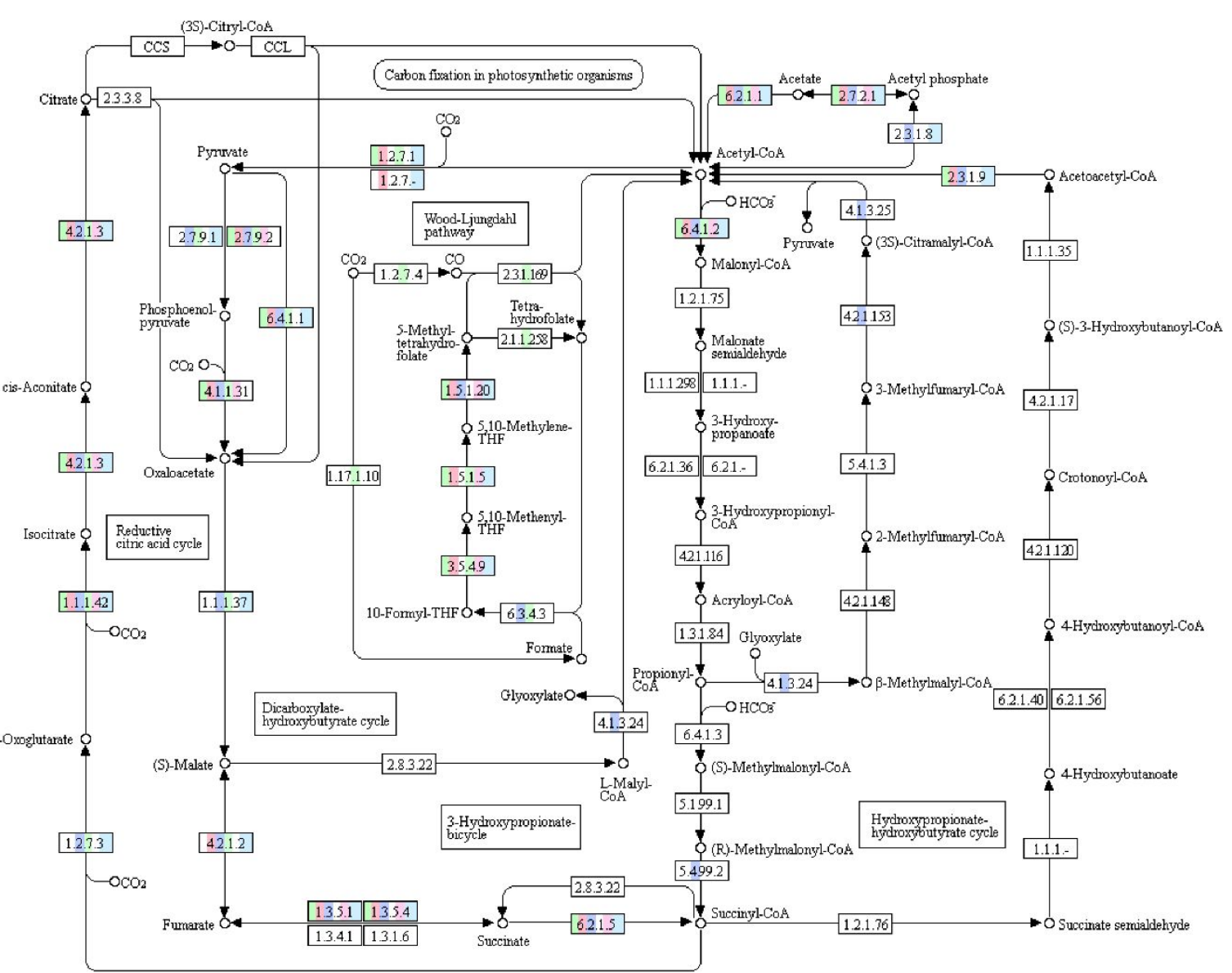

92

00720 4/24/19
(c) Kanehisa Laboratonies

93 Fig. S13. The map of the genes related to the carbon fixation pathways in prokaryotes in

94 each MAG.

95 


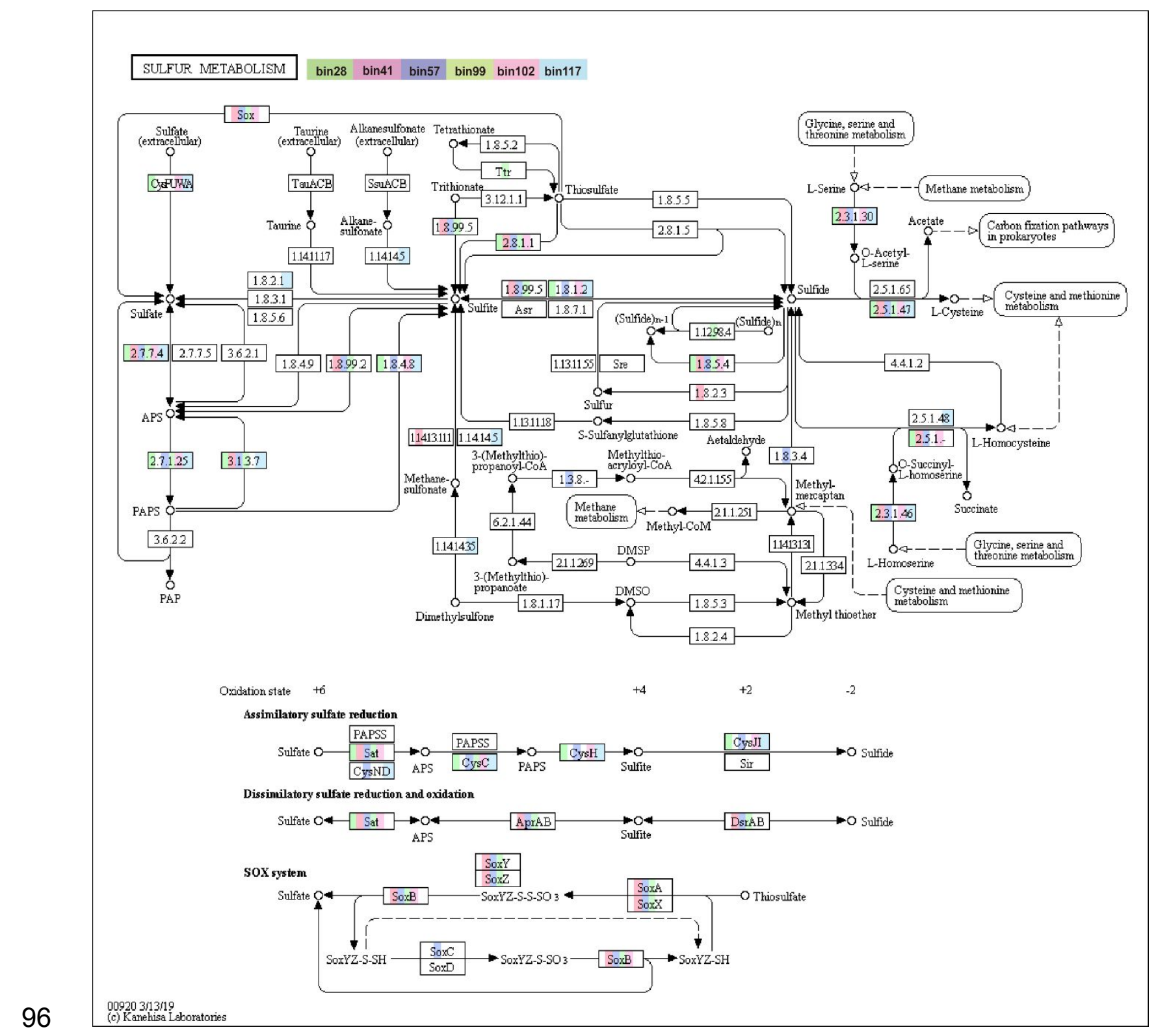

97 Fig. S14. The completeness of the genes related to the sulfur metabolism in each MAG.

98 
99 Table S1. Site information for amplicon libraries

\begin{tabular}{|c|c|c|c|c|}
\hline Sample ID & Coordinates & Region & Major contaminants & Type \\
\hline HYQ01 & $27^{\circ} 44^{\prime} \mathrm{N} 111^{\circ} 28^{\prime} \mathrm{E}$ & Xikuangshan & Antimony & Soil \\
\hline HYQ02 & $27^{\circ} 44^{\prime} \mathrm{N} 111^{\circ} 28^{\prime} \mathrm{E}$ & Xikuangshan & Antimony & Soil \\
\hline HYQ03 & $27^{\circ} 44^{\prime} \mathrm{N} 111^{\circ} 28^{\prime} \mathrm{E}$ & Xikuangshan & Antimony & Soil \\
\hline HYQ04 & $27^{\circ} 44^{\prime} \mathrm{N} 111^{\circ} 28^{\prime} \mathrm{E}$ & Xikuangshan & Antimony & Soil \\
\hline HYQ05 & $27^{\circ} 44^{\prime} \mathrm{N} 111^{\circ} 28^{\prime} \mathrm{E}$ & Xikuangshan & Antimony & Soil \\
\hline HYQ06 & $27^{\circ} 44^{\prime} \mathrm{N} 111^{\circ} 28^{\prime} \mathrm{E}$ & Xikuangshan & Antimony & Soil \\
\hline HYQ07 & $27^{\circ} 44^{\prime} \mathrm{N} 111^{\circ} 28^{\prime} \mathrm{E}$ & Xikuangshan & Antimony & Tailing \\
\hline HYQ08 & $27^{\circ} 44^{\prime} \mathrm{N} 111^{\circ} 28^{\prime} \mathrm{E}$ & Xikuangshan & Antimony & Tailing \\
\hline HYQ09 & $27^{\circ} 44^{\prime} \mathrm{N} 111^{\circ} 28^{\prime} \mathrm{E}$ & Xikuangshan & Antimony & Tailing \\
\hline HYQ10 & $27^{\circ} 44^{\prime} \mathrm{N} 111^{\circ} 28^{\prime} \mathrm{E}$ & Xikuangshan & Antimony & Tailing \\
\hline HYQ11 & $27^{\circ} 44^{\prime} \mathrm{N} 111^{\circ} 28^{\prime} \mathrm{E}$ & Xikuangshan & Antimony & Soil \\
\hline HYQ12 & $27^{\circ} 44^{\prime} \mathrm{N} 111^{\circ} 28^{\prime} \mathrm{E}$ & Xikuangshan & Antimony & Soil \\
\hline HYQ13 & $27^{\circ} 44^{\prime} \mathrm{N} 111^{\circ} 28^{\prime} \mathrm{E}$ & Xikuangshan & Antimony & Soil \\
\hline HYQ14 & $27^{\circ} 44^{\prime} \mathrm{N} 111^{\circ} 28^{\prime} \mathrm{E}$ & Xikuangshan & Antimony & Soil \\
\hline HYQ15 & $29^{\circ} 35^{\prime} \mathrm{N} 111^{\circ} 23^{\prime} \mathrm{E}$ & Shimen & Arsenic & Soil \\
\hline HYQ16 & $29^{\circ} 35^{\prime} \mathrm{N} 111^{\circ} 23^{\prime} \mathrm{E}$ & Shimen & Arsenic & Soil \\
\hline HYQ17 & $29^{\circ} 35^{\prime} \mathrm{N} 111^{\circ} 23^{\prime} \mathrm{E}$ & Shimen & Arsenic & Soil \\
\hline HYQ18 & $29^{\circ} 35^{\prime} \mathrm{N} 111^{\circ} 23^{\prime} \mathrm{E}$ & Shimen & Arsenic & Soil \\
\hline HYQ19 & $29^{\circ} 35^{\prime} \mathrm{N} 111^{\circ} 23^{\prime} \mathrm{E}$ & Shimen & Arsenic & Soil \\
\hline HYQ20 & $29^{\circ} 35^{\prime} \mathrm{N} 111^{\circ} 23^{\prime} \mathrm{E}$ & Shimen & Arsenic & Soil \\
\hline HYQ21 & $29^{\circ} 35^{\prime} \mathrm{N} 111^{\circ} 23^{\prime} \mathrm{E}$ & Shimen & Arsenic & Soil \\
\hline HYQ22 & $29^{\circ} 35^{\prime} \mathrm{N} 111^{\circ} 23^{\prime} \mathrm{E}$ & Shimen & Arsenic & Soil \\
\hline HYQ23 & $29^{\circ} 35^{\prime} \mathrm{N} 111^{\circ} 23^{\prime} \mathrm{E}$ & Shimen & Arsenic & Soil \\
\hline HYQ24 & $29^{\circ} 35^{\prime} \mathrm{N} 111^{\circ} 23^{\prime} \mathrm{E}$ & Shimen & Arsenic & Tailing \\
\hline HYQ25 & $29^{\circ} 35^{\prime} \mathrm{N} 111^{\circ} 23^{\prime} \mathrm{E}$ & Shimen & Arsenic & Tailing \\
\hline HYQ26 & $29^{\circ} 35^{\prime} \mathrm{N} 111^{\circ} 23^{\prime} \mathrm{E}$ & Shimen & Arsenic & Tailing \\
\hline HYQ27 & $25^{\circ} 49^{\prime} \mathrm{N} 107^{\circ} 32^{\prime} \mathrm{E}$ & Dushan & Lead, Zinc & Tailing \\
\hline HYQ28 & $25^{\circ} 49^{\prime} \mathrm{N} 107^{\circ} 32^{\prime} \mathrm{E}$ & Dushan & Lead, Zinc & Tailing \\
\hline HYQ29 & $25^{\circ} 49^{\prime} \mathrm{N} 107^{\circ} 32^{\prime} \mathrm{E}$ & Dushan & Lead, Zinc & Tailing \\
\hline HYQ30 & $25^{\circ} 49^{\prime} \mathrm{N} 107^{\circ} 32^{\prime} \mathrm{E}$ & Dushan & Lead, Zinc & Tailing \\
\hline HYQ31 & $25^{\circ} 49^{\prime} \mathrm{N} 107^{\circ} 32^{\prime} \mathrm{E}$ & Dushan & Lead, Zinc & Tailing \\
\hline HYQ32 & $25^{\circ} 49^{\prime} \mathrm{N} 107^{\circ} 32^{\prime} \mathrm{E}$ & Dushan & Lead, Zinc & Soil \\
\hline HYQ33 & $25^{\circ} 49^{\prime} \mathrm{N} 107^{\circ} 32^{\prime} \mathrm{E}$ & Dushan & Lead, Zinc & Soil \\
\hline HYQ34 & $25^{\circ} 49^{\prime} \mathrm{N} 107^{\circ} 32^{\prime} \mathrm{E}$ & Dushan & Lead, Zinc & Soil \\
\hline HYQ35 & $25^{\circ} 49^{\prime} \mathrm{N} 107^{\circ} 32^{\prime} \mathrm{E}$ & Dushan & Lead, Zinc & Soil \\
\hline HYQ36 & $25^{\circ} 49^{\prime} \mathrm{N} 107^{\circ} 32^{\prime} \mathrm{E}$ & Dushan & Lead, Zinc & Soil \\
\hline
\end{tabular}




\begin{tabular}{|c|c|c|c|c|}
\hline HYQ37 & $25^{\circ} 49^{\prime} \mathrm{N} 107^{\circ} 32^{\prime} \mathrm{E}$ & Dushan & Lead, Zinc & Soil \\
\hline HYQ38 & $25^{\circ} 49^{\prime} \mathrm{N} 107^{\circ} 32^{\prime} \mathrm{E}$ & Dushan & Lead, Zinc & Soil \\
\hline HYQ39 & $25^{\circ} 49^{\prime} \mathrm{N} 107^{\circ} 32^{\prime} \mathrm{E}$ & Dushan & Lead, Zinc & Soil \\
\hline HYQ40 & $25^{\circ} 49^{\prime} \mathrm{N} 107^{\circ} 32^{\prime} \mathrm{E}$ & Dushan & Lead, Zinc & Soil \\
\hline HYQ41 & $25^{\circ} 49^{\prime} \mathrm{N} 107^{\circ} 32^{\prime} \mathrm{E}$ & Dushan & Lead, Zinc & Soil \\
\hline HYQ42 & $25^{\circ} 49^{\prime} \mathrm{N} 107^{\circ} 32^{\prime} \mathrm{E}$ & Dushan & Lead, Zinc & Soil \\
\hline HYQ43 & $25^{\circ} 50^{\prime} \mathrm{N} 105^{\circ} 13^{\prime} \mathrm{E}$ & Qinglong & Antimony & Tailing \\
\hline HYQ44 & $25^{\circ} 50^{\prime} \mathrm{N} 105^{\circ} 13^{\prime} \mathrm{E}$ & Qinglong & Antimony & Tailing \\
\hline HYQ45 & $25^{\circ} 50^{\prime} \mathrm{N} 105^{\circ} 13^{\prime} \mathrm{E}$ & Qinglong & Antimony & Tailing \\
\hline HYQ46 & $25^{\circ} 50^{\prime} \mathrm{N} 105^{\circ} 13^{\prime} \mathrm{E}$ & Qinglong & Antimony & Tailing \\
\hline HYQ47 & $25^{\circ} 50^{\prime} \mathrm{N} 105^{\circ} 13^{\prime} \mathrm{E}$ & Qinglong & Antimony & Tailing \\
\hline HYQ48 & $25^{\circ} 50^{\prime} \mathrm{N} 105^{\circ} 13^{\prime} \mathrm{E}$ & Qinglong & Antimony & Tailing \\
\hline HYQ49 & $25^{\circ} 50^{\prime} \mathrm{N} 105^{\circ} 13^{\prime} \mathrm{E}$ & Qinglong & Antimony & Tailing \\
\hline HYQ50 & $25^{\circ} 50^{\prime} \mathrm{N} 105^{\circ} 13^{\prime} \mathrm{E}$ & Qinglong & Antimony & Tailing \\
\hline HYQ51 & $25^{\circ} 50^{\prime} \mathrm{N} 105^{\circ} 13^{\prime} \mathrm{E}$ & Qinglong & Antimony & Tailing \\
\hline HYQ52 & $25^{\circ} 50^{\prime} \mathrm{N} 105^{\circ} 13^{\prime} \mathrm{E}$ & Qinglong & Antimony & Tailing \\
\hline HYQ53 & $25^{\circ} 50^{\prime} \mathrm{N} 105^{\circ} 13^{\prime} \mathrm{E}$ & Qinglong & Antimony & Tailing \\
\hline HYQ54 & $25^{\circ} 50^{\prime} \mathrm{N} 105^{\circ} 13^{\prime} \mathrm{E}$ & Qinglong & Antimony & Tailing \\
\hline HYQ55 & $25^{\circ} 50^{\prime} \mathrm{N} 105^{\circ} 13^{\prime} \mathrm{E}$ & Qinglong & Antimony & Tailing \\
\hline HYQ56 & $25^{\circ} 50^{\prime} \mathrm{N} 105^{\circ} 13^{\prime} \mathrm{E}$ & Qinglong & Antimony & Tailing \\
\hline HYQ57 & $25^{\circ} 50^{\prime} \mathrm{N} 105^{\circ} 13^{\prime} \mathrm{E}$ & Qinglong & Antimony & Tailing \\
\hline HYQ58 & $24^{\circ} 51^{\prime} \mathrm{N} 107^{\circ} 39^{\prime} \mathrm{E}$ & Nandan & Lead, Zinc & Tailing \\
\hline HYQ59 & $24^{\circ} 51^{\prime} \mathrm{N} 107^{\circ} 39^{\prime} \mathrm{E}$ & Nandan & Lead, Zinc & Tailing \\
\hline HYQ60 & $24^{\circ} 51^{\prime} \mathrm{N} 107^{\circ} 39^{\prime} \mathrm{E}$ & Nandan & Lead, Zinc & Tailing \\
\hline HYQ61 & $24^{\circ} 51^{\prime} N 107^{\circ} 39^{\prime} \mathrm{E}$ & Nandan & Lead, Zinc & Tailing \\
\hline HYQ62 & $24^{\circ} 51^{\prime} N 107^{\circ} 39^{\prime} \mathrm{E}$ & Nandan & Lead, Zinc & Tailing \\
\hline HYQ63 & $24^{\circ} 51^{\prime} \mathrm{N} 107^{\circ} 39^{\prime} \mathrm{E}$ & Nandan & Lead, Zinc & Tailing \\
\hline HYQ64 & $24^{\circ} 51^{\prime} \mathrm{N} 107^{\circ} 39^{\prime} \mathrm{E}$ & Nandan & Lead, Zinc & Tailing \\
\hline HYQ65 & $24^{\circ} 51^{\prime} \mathrm{N} 107^{\circ} 39^{\prime} \mathrm{E}$ & Nandan & Lead, Zinc & Tailing \\
\hline HYQ66 & $24^{\circ} 51^{\prime} \mathrm{N} 107^{\circ} 39^{\prime} \mathrm{E}$ & Nandan & Lead, Zinc & Tailing \\
\hline HYQ67 & $24^{\circ} 51^{\prime} \mathrm{N} 107^{\circ} 39^{\prime} \mathrm{E}$ & Nandan & Lead, Zinc & Tailing \\
\hline HYQ68 & $26^{\circ} 58^{\prime} \mathrm{N} 106^{\circ} 40^{\prime} \mathrm{E}$ & Xiuwen & Arsenic, Lead, Zinc & Soil \\
\hline HYQ69 & $26^{\circ} 58^{\prime} \mathrm{N} 106^{\circ} 40^{\prime} \mathrm{E}$ & Xiuwen & Arsenic, Lead, Zinc & Soil \\
\hline HYQ70 & $26^{\circ} 58^{\prime} \mathrm{N} 106^{\circ} 40^{\prime} \mathrm{E}$ & Xiuwen & Arsenic, Lead, Zinc & Soil \\
\hline HYQ71 & $26^{\circ} 58^{\prime} \mathrm{N} 106^{\circ} 40^{\prime} \mathrm{E}$ & Xiuwen & Arsenic, Lead, Zinc & Soil \\
\hline HYQ72 & $26^{\circ} 58^{\prime} \mathrm{N} 106^{\circ} 40^{\prime} \mathrm{E}$ & Xiuwen & Arsenic, Lead, Zinc & Soil \\
\hline HYQ73 & $26^{\circ} 58^{\prime} \mathrm{N} 106^{\circ} 40^{\prime} \mathrm{E}$ & Xiuwen & Arsenic, Lead, Zinc & Soil \\
\hline HYQ74 & $26^{\circ} 58^{\prime} \mathrm{N} 106^{\circ} 40^{\prime} \mathrm{E}$ & Xiuwen & Arsenic, Lead, Zinc & Soil \\
\hline HYQ75 & $26^{\circ} 58^{\prime} \mathrm{N} 106^{\circ} 40^{\prime} \mathrm{E}$ & Xiuwen & Arsenic, Lead, Zinc & Soil \\
\hline
\end{tabular}




\begin{tabular}{|l|l|l|l|l|}
\hline HYQ76 & $25^{\circ} 50^{\prime} \mathrm{N} 105^{\circ} 13^{\prime} \mathrm{E}$ & Qinglong & Antimony & Soil \\
\hline HYQ77 & $25^{\circ} 50^{\prime} \mathrm{N} 105^{\circ} 13^{\prime} \mathrm{E}$ & Qinglong & Antimony & Soil \\
\hline
\end{tabular}

100

101 
102 Table S2. Site information for acetylene reduction assay

\begin{tabular}{|c|c|c|c|c|}
\hline Sample ID & Coordinates & Region & Major contaminants & Type \\
\hline ARA01 & $27^{\circ} 44^{\prime} \mathrm{N} 111^{\circ} 28^{\prime} \mathrm{E}$ & Xikuangshan & Antimony & Soil \\
\hline ARA02 & $27^{\circ} 44^{\prime} \mathrm{N} 111^{\circ} 28^{\prime} \mathrm{E}$ & Xikuangshan & Antimony & Soil \\
\hline ARA03 & $27^{\circ} 44^{\prime} \mathrm{N} 111^{\circ} 28^{\prime} \mathrm{E}$ & Xikuangshan & Antimony & Tailing \\
\hline ARA04 & $27^{\circ} 44^{\prime} \mathrm{N} 111^{\circ} 28^{\prime} \mathrm{E}$ & Xikuangshan & Antimony & Tailing \\
\hline ARA05 & $29^{\circ} 35^{\prime} \mathrm{N} 111^{\circ} 23^{\prime} \mathrm{E}$ & Shimen & Arsenic & Soil \\
\hline ARA06 & $29^{\circ} 35^{\prime} \mathrm{N} 111^{\circ} 23^{\prime} \mathrm{E}$ & Shimen & Arsenic & Soil \\
\hline ARA07 & $29^{\circ} 35^{\prime} \mathrm{N} 111^{\circ} 23^{\prime} \mathrm{E}$ & Shimen & Arsenic & Soil \\
\hline ARA08 & $29^{\circ} 35^{\prime} \mathrm{N} 111^{\circ} 23^{\prime} \mathrm{E}$ & Shimen & Arsenic & Tailing \\
\hline ARA09 & $29^{\circ} 35^{\prime} \mathrm{N} 111^{\circ} 23^{\prime} \mathrm{E}$ & Shimen & Arsenic & Tailing \\
\hline ARA10 & $29^{\circ} 35^{\prime} \mathrm{N} 111^{\circ} 23^{\prime} \mathrm{E}$ & Shimen & Arsenic & Tailing \\
\hline ARA11 & $25^{\circ} 49^{\prime} \mathrm{N} 107^{\circ} 32^{\prime} \mathrm{E}$ & Dushan & Lead, Zinc & Soil \\
\hline ARA12 & $25^{\circ} 49^{\prime} \mathrm{N} 107^{\circ} 32^{\prime} \mathrm{E}$ & Dushan & Lead, Zinc & Soil \\
\hline ARA13 & $25^{\circ} 49^{\prime} \mathrm{N} 107^{\circ} 32^{\prime} \mathrm{E}$ & Dushan & Lead, Zinc & Tailing \\
\hline ARA14 & $25^{\circ} 49^{\prime} \mathrm{N} 107^{\circ} 32^{\prime} \mathrm{E}$ & Dushan & Lead, Zinc & Tailing \\
\hline ARA15 & $25^{\circ} 49^{\prime} \mathrm{N} 107^{\circ} 32^{\prime} \mathrm{E}$ & Dushan & Lead, Zinc & Tailing \\
\hline ARA16 & $24^{\circ} 51^{\prime} \mathrm{N} 107^{\circ} 39^{\prime} \mathrm{E}$ & Nandan & Lead, Zinc & Tailing \\
\hline ARA17 & $24^{\circ} 51^{\prime} \mathrm{N} 107^{\circ} 39^{\prime} \mathrm{E}$ & Nandan & Lead, Zinc & Tailing \\
\hline ARA18 & $24^{\circ} 51^{\prime} \mathrm{N} 107^{\circ} 39^{\prime} \mathrm{E}$ & Nandan & Lead, Zinc & Tailing \\
\hline ARA19 & $26^{\circ} 58^{\prime} \mathrm{N} 106^{\circ} 40^{\prime} \mathrm{E}$ & Xiuwen & Arsenic, Lead, Zinc & Soil \\
\hline ARA20 & $26^{\circ} 58^{\prime} \mathrm{N} 106^{\circ} 40^{\prime} \mathrm{E}$ & Xiuwen & Arsenic, Lead, Zinc & Soil \\
\hline ARA21 & $25^{\circ} 50^{\prime} \mathrm{N} 105^{\circ} 13^{\prime} \mathrm{E}$ & Qinglong & Antimony & Tailing \\
\hline ARA22 & $25^{\circ} 50^{\prime} \mathrm{N} 105^{\circ} 13^{\prime} \mathrm{E}$ & Qinglong & Antimony & Tailing \\
\hline ARA23 & $25^{\circ} 50^{\prime} \mathrm{N} 105^{\circ} 13^{\prime} \mathrm{E}$ & Qinglong & Antimony & Soil \\
\hline
\end{tabular}


105 Table S3. Summary of qPCR protocols

\begin{tabular}{|c|c|c|c|c|}
\hline Gene & Primer set & $\begin{array}{c}\text { Standard Curve } \\
\text { (Copies) }\end{array}$ & Running conditions & Reference \\
\hline $\begin{array}{l}16 S \\
\text { rRNA }\end{array}$ & 331F/518R & $\begin{array}{c}2.76 \times 10^{3} \text { to } \\
2.76 \times 10^{8}\end{array}$ & $\begin{array}{c}2 \min \text { at } 50{ }^{\circ} \mathrm{C}, 2 \text { min at } 95^{\circ} \mathrm{C} \text {, } \\
\text { followed by } 40 \text { cycles at } 95^{\circ} \mathrm{C} \\
\text { for } 15 \mathrm{~s}, 55^{\circ} \mathrm{C} \text { for } 15 \mathrm{~s} \text { and } 72^{\circ} \mathrm{C} \\
\text { for } 1 \mathrm{~min}\end{array}$ & [32] \\
\hline nifH & $\mathrm{polF} / \mathrm{polR}$ & $\begin{array}{l}3.2 \times 10^{2} \text { to } \\
3.2 \times 10^{7}\end{array}$ & $\begin{array}{l}2 \text { min at } 50{ }^{\circ} \mathrm{C}, 2 \text { min at } 95^{\circ} \mathrm{C} \text {, } \\
\text { followed by } 45 \text { cycles of } 95^{\circ} \mathrm{C} \\
\text { for } 15 \mathrm{~s}, 63^{\circ} \mathrm{C} \text { for } 1 \mathrm{~min}\end{array}$ & [27], [33] \\
\hline$c b b L$ & $\begin{array}{c}\text { cbbLR1F/cbbL } \\
\text { 1intR }\end{array}$ & $\begin{array}{c}4.0 \times 10^{3} \text { to } \\
4.0 \times 10^{9}\end{array}$ & $\begin{array}{c}10 \mathrm{~min} \text { at } 95^{\circ} \mathrm{C} \text {, followed by } 50 \\
\text { cycles of } 95^{\circ} \mathrm{C} \text { for } 30 \mathrm{~s}, 61.2^{\circ} \mathrm{C} \text { for } \\
30 \mathrm{~s} \text {, and } 72{ }^{\circ} \mathrm{C} \text { for } 30 \mathrm{~s}\end{array}$ & [34] \\
\hline soxB & 710F/1184R & $\begin{array}{l}3.2 \times 10^{2} \text { to } \\
3.2 \times 10^{7}\end{array}$ & $\begin{array}{c}2 \mathrm{~min} \text { at } 50{ }^{\circ} \mathrm{C}, 2 \mathrm{~min} \text { at } 95^{\circ} \mathrm{C} \text {, } \\
\text { followed by } 45 \text { cycles of } 95^{\circ} \mathrm{C} \text { for } \\
15 \mathrm{~s}, 63^{\circ} \mathrm{C} \text { for } 1 \mathrm{~min}\end{array}$ & [35] \\
\hline aioA & $\begin{array}{l}\text { aoxBM1-2F/ } \\
\text { aoxBM 2-1R }\end{array}$ & $\begin{array}{l}2.8 \times 10^{1} \text { to } \\
2.8 \times 10^{7}\end{array}$ & $\begin{array}{l}10 \mathrm{~min} \text { at } 95^{\circ} \mathrm{C} \text {, followed by } 50 \\
\text { cycles of } 95^{\circ} \mathrm{C} \text { for } 30 \mathrm{~s}, 59^{\circ} \mathrm{C} \text { for } \\
30 \mathrm{~s} \text {, and } 72^{\circ} \mathrm{C} \text { for } 50 \mathrm{~s}\end{array}$ & [36] \\
\hline
\end{tabular}


108 Table S4. Site information for metagenomic libraries

\begin{tabular}{|l|l|l|l|l|}
\hline Sample ID & Coordinates & Region & Major contaminants & Type \\
\hline LMC14 & $26^{\circ} 58^{\prime} \mathrm{N} 106^{\circ} 40^{\prime} \mathrm{E}$ & Xiuwen & Arsenic, Lead, Zinc & Soil \\
\hline LMC22 & $26^{\circ} 58^{\prime} \mathrm{N} 106^{\circ} 40^{\prime} \mathrm{E}$ & Xiuwen & Arsenic, Lead, Zinc & Soil \\
\hline YSYL1-1 & $29^{\circ} 35^{\prime} \mathrm{N} 111^{\circ} 23^{\prime} \mathrm{E}$ & Xikuangshan & Antimony & Soil \\
\hline YSYL2-1 & $29^{\circ} 35^{\prime} \mathrm{N} 111^{\circ} 23^{\prime} \mathrm{E}$ & Xikuangshan & Antimony & Soil \\
\hline CSWK08 & $24^{\circ} 51^{\prime} \mathrm{N} 107^{\circ} 39^{\prime} \mathrm{E}$ & Nandan & Lead, Zinc & Tailing \\
\hline CSWK28 & $24^{\circ} 51^{\prime} \mathrm{N} 107^{\circ} 39^{\prime} \mathrm{E}$ & Nandan & Lead, Zinc & Tailing \\
\hline XKSWK3 & $27^{\circ} 44^{\prime} \mathrm{N} 111^{\circ} 28^{\prime} \mathrm{E}$ & Xikuangshan & Antimony & Tailing \\
\hline XKSWK8 & $27^{\circ} 44^{\prime} \mathrm{N} 111^{\circ} 28^{\prime} \mathrm{E}$ & Xikuangshan & Antimony & Tailing \\
\hline
\end{tabular}

